\title{
Faculty Development Can Change the Culture of a College
}

\section{Ann S. Ferren}

The American University

October 28,1980

Dear Colleague:

Too rarely do we actually have-or take - the opportunity to share ideas that excite us with members of other disciplines. In order to stimulate intellectual discussion among the College faculty on matters of mutual interest, the Faculty Development Committee is considering the formation of a Faculty Colloquium. We would appreciate your considered opinion and advice in connection with this project.

The Committee believes that one of the important goals of the faculty development program should be to promote awareness and understanding of the intellectual interests of our colleagues in other disciplines and, at the same time, to strengthen our grasp of the values and convictions we all share. We meet only too often as adversaries in academic politics, arguing for a bigger slice of budget pie or a better position in the latest curriculum planning exercise. A Faculty Colloquium would give us a chance to transcend such encounters, for a while, and engage in some free dialogue about the things that matter most to us.

This letter, sent to 210 faculty members in the College of Arts and Sciences at the American University, began what has become an annual tradition - the Faculty Colloquium. No faculty development activity has had such a significant long-term effect on the culture of the college. 


\section{Initiating a Faculty Development Program}

Before initiating a comprehensive faculty development program, the College of Arts and Sciences, with over $\mathbf{2 0 0}$ faculty members organized in 18 different units, had limited self-awareness and no shared feeling of a common mission. Faculty members taught, did research, and came and went at different hours, often missing colleagues for a semester at a time. Faculty identified with their departments, not the college. And most of the faculty enjoyed this freedom and expressed no need for greater commitment to the larger institution.

In 1979, the college was awarded a large foundation grant to develop curricula and stimulate faculty renewal. The first year of the program included a series of workshops on teaching, a writing-across-the-curriculum project, a classroom consultation program, and a small grants program for research and teaching development. In that first year, 150 faculty members participated in at least one activity; the advisory committee, the director of the program, and the dean of the college thus deemed the program a success so far.

At the beginning of the second year, the director interviewed a number of faculty members as part of a needs assessment strategy aimed at building on the successes of the previous year and broadening participation. In each interview, faculty expressed enthusiasm about the variety of activities and assured the director that the program was meeting their expectations while stimulating their interest in teaching, course development, and research. Another theme emerged from the comments-the value of "meeting faculty from other departments" who shared similar concerns.

One senior faculty member, however, while positive about the program, said, "But there is nothing in it for me. I don't have a problem." The always optimistic director asked, "Well, what do you want?" "I want a real college," came the reply. And with considerable wistfulness this senior philosophy professor described what he missed most - real intellectual stimulation from colleagues. He declared the college as barren as the asphalt parking lot outside his office window.

The professor's call for "a real college" disturbed the director. While the faculty development program was effective, it did have something of a remedial or "fix-it" approach. Furthermore, one reason faculty clearly liked the program was that the small grants program gave them support for special projects - but this program strengthened only individuals with their separate interests. The philosophy professor was right; there was 
little about the faculty development program in its conception that was designed to directly nourish and strengthen the college overall.

\section{Planning for Intellectual Community}

The faculty development committee began to discuss ways to increase connections among members of the faculty. Membership in an intellectual community, similar to that available in small liberal arts colleges, was cited as the ideal to be emulated. Could a mid-sized institution in an exciting city become a focus for intellectual life? Could the College of Arts and Sciences compete with the Wilson Center, the Smithsonian, the Kennnedy Center, or the Folger?

The idea of sponsoring a two- to three-day colloquium emerged slowly as an opportunity for members of the faculty to come together as colleagues for intellectual nourishment. There would be no problem to fix, unlike the workshops on "motivating students" or "responding to the needs of international students." There would be no expertise offered, unlike the presentations on "students in the '80's" and "learning styles of college freshmen." There would be no specified tasks to accomplish, unlike the task forces on developing an interdisciplinary humanities course and integrating computing into the instructional program. The faculty development committee would not set the agenda. They began to talk about the potential colloquium experience as being "for free."

With some concern, the committee sent out a letter of inquiry and a planning questionnaire. Close to 50 responses came by return mail. Immediately, the committee knew they had struck a responsive chord clearly, more than one thoughtful philosophy professor found the idea appealing. A faculty planning committee, representing different disciplines and ranks, was selected from among the respondents. The committee met weekly for months to plan the program, select books, and identify potential participants. Throughout the entire planning time, even though committee members were engaged themselves in a rich and challenging dialogue about issues, they kept asking, "What if it doesn't work? What if the faculty have nothing to say?" After the first Colloquium, the planning committees never asked those questions again.

\section{Designing a Colloquium}

The first Faculty Colloquium focused on a timely theme accessible to all: "America: The Two Hundred Year Experiment." Because the committee feared their colleagues might not have anything to say, they selected 
six books as the focus for discussion. Each book was carefully chosen to provide point and counterpoint on the theme-for example, Richard Barnet's The Lean Years was paired with Thoreau's Walden. Participants later confessed they had somehow missed reading some of the "classics"; thus, in successive years, careful attention was paid to selecting readings that balanced the old with the new. The Colloquium, if nothing else, would help faculty members to fill gaps in their background, to appreciate the interplay of ideas from classic works and the later modifications and outright challenges to those ideas, and to recognize anew how difficult it is to read the primary sources which so many faculty members blithely assign to their students.

The Colloquium was set for the three days between final exams and commencement to assure maximum faculty availability. It has turned out over the years that this timing also makes the Colloquium feel like a celebration, a collegial closing to the academic year, and a ceremonial launching into a summer of scholarly activity. Though the time commitment deterred some participants, having three days together promoted fellowship and encouraged extended conversations. Food was as thoughtfully and plentifully planned as the readings. In later years, the colloquia have been scaled back to a day and a half. And an increasingly healthconscious faculty has opted for bran muffins instead of doughnuts.

Forty-one faculty members came to that first Colloquium and that number has remained roughly the same for eight years. There are always new faces as well as many returning participants. Only six faculty in the college, however, can claim to have been to every one of the colloquia. The format that first year called for several ten-minute presentations on each of the readings, followed by either large or small group discussion. The format required each of the 50 participants to accept a role designed to promote direct engagement with the material.

Anxiety was the most striking phenomenon in that first year. Faculty called repeatedly to be sure they understood what was expected. Then they called to see if they really had to do ten minutes. Then they called to see who would be there. Not until the first evening did the source of the concerns become clear: the faculty did not know each other. The faculty planning committee was about to host a large party for strangers. And they all acted as if their reputations were at stake. Needless to say, the presentations were impressive, the discussions were rewarding, and the participants congratulated each other for weeks about the intellectual excitement of the three days. In response to the evaluation question "What has been of most value?" a faculty member summed up the views 
of many by saying, "thinking about ideas I might never encounter without the stimulus of the Colloquium."

\section{Planning Successive Colloquia}

The next year, with dread about how much hand-holding was necessary, the faculty development committee decided to start the planning early. Unexpectedly, each faculty member invited to be on the Colloquium planning committee was happy to serve. In later years, faculty would complain that they had not had a chance to be on the Colloquium committee-clearly an unusual issue, since faculty in general are not known to complain about not having enough committee work.

"Ideas that Challenge Beliefs" was chosen as the theme for the second Colloquium. Darwin and Marx were selected as examples of individuals whose ideas continue to provide intellectual challenge and provoke controversy. Reading were carefully selected and distributed early. The format was also designed to be provocative and discussion leaders were assigned for each presentation. During the discussions, faculty openly argued about how to reconcile faith and science. Stimulated by Ollman and Vernoff's The Left Academy, they opened up discussion of ideological rifts that had divided them in the past. Throughout, faculty members gave personal testimony about what it means to be a believer. The timidity of the previous year was not evident. In an evaluation note, one participant remarked, "reading Marx for the first time - I'm not ashamed to admit just delighted to have the chance."

By the third year, the planning committee had enough confidence to call it the "annual" Colloquium. Around the theme "The Workings of Minds," faculty were asked, "Can machines think? Do males and females think differently? Can we understand cultures that are not ours? What is understanding? What is intelligence?" Gilligan's In a Different Voice, Said's Orientalism, and McCorduck's Machines Who Think provided focus. An increasingly confident faculty gave teaching demonstrations to bring life to some of the concepts. In later years, faculty would note how many of the readings from previous colloquia showed up in the bookstore as required readings in courses.

Each year, it has become clearer what it means to trust colleagues enough to engage directly and publicly and honestly. Each year, faculty are less and less interested in small group discussion and more interested in keeping the large group together. In 1984, we could not resist taking another look at Orwell's classic juxtaposed with Mill's On Liberty. The committee developed formal debate cases on current issues of freedom 
and responsibility and the relation of the individual to the state in order to extend the themes from the readings.

One year, faculty expressed interest in a more affective colloquium drawing upon art, music, and opera. We immersed ourselves in a feast of ideas and experience supported by reading Gay's The Enlightenment, May's The Enlightenment in America, and Darnton's The Great Cat Massacre to answer the question, "Why was the 18th century called the Age of Enlightenment?" Another year, the planning committee responded to faculty interests and selected the very challenging theme "Gender, Power, and Knowledge." Trust built over the years enabled faculty members to read broadly from Perkins' Herland to Keller's Reflections on Gender and Science and ultimately raise questions about equity in the academy.

Through the colloquia, faculty have been stretched by publicly analyzing issues of deep concern to academics. They talk about how the ideas and values they hold inform their teaching and their campus life. Last year, inevitably, Bloom and Hirsch were the focus for discussion, allowing faculty to reaffirm their understanding of the role of the liberal arts in higher education and the role of the college within the university. Eight years later, the college now finds itself "a real college."

\section{Governing Norms for the Colloquium}

The purpose of the Colloquium is to build community. From the beginning, norms were set deeming that all faculty would share equally in the experience. Every now and then, a faculty member who likes having an audience slips from the collegial "there are no experts here" mode into a lecture mode. Some member of the planning committee gently intervenes. Over the years, participants have largely been able to set aside their more dominating, "teacher" habits and to function as colleagues. Invariably, because of changes in participants, the norms must be set and reset each year. Just as a faculty member is about to violate the norms, such as speaking too long, an old hand will gently say, "Let's give others a chance." If someone begins to take over, another will note, "There are no experts here today, just interested parties."

These norms are critical and have assured that humanists get to talk about science without apology. Anthropologists get to comment on art. Historians can lead discussions on poetry. Marxist sociologists, conservative economists, and feminist art historians can all speak their minds without apology, a chip on their shoulder, or fear. We have discovered that as a faculty, we can have differences, yet be intellectual friends. 
There have been moving moments - a faculty member illustrated a point by talking about his mother's courage; another faculty member confessed to thinking of leaving the university. Such unguarded moments have helped us to appreciate our strengths and frailties, to like each other more.

One year, every speaker wore a carefully selected hat to signal the theme of the presentation - a philosopher brought down the house when he outlined the challenges to tradition while wearing a fireman's hat. Another year, a male biologist described scientific explanations of gender differences dressed as Mother Nature, complete with bright red lipstick, dress, hat, and high heels. His presentation challenged so many boundaries that, throughout the day, participants analyzed the multilevel messages.

Over the years, the college has changed. Faculty members know each other far better intellectually and personally. There is increased respect and less protection of turf. Recently, this considerable reservoir of good will turned into unanimous support for a new general education program. Clearly, the faculty development program has improved the quality of life within the college.

\section{Lessons Learned}

The Faculty Colloquium can be adapted to any setting and provide a valuable complement to an ongoing faculty development program. Careful planning is the secret of success, and experienced faculty developers are well aware of the importance of timing, format, materials, and participation. What may not be as apparent is the importance of the Colloquium's themes in developing intellectual community. Among the lessons learned are the following:

1. The theme and guiding questions for the Colloquium must be really challenging and stretch the faculty. Once faculty members understand the purpose of the Colloquium, they do not feel intimidated by their colleagues. They feel joined by an impressive and talented group of peers committed to the struggle to understand new material.

2. The themes need to balance the interests of humanists, social scientists, and natural scientists to reveal the full range of the intellectual community. In some of the early sessions, the scientists tried to claim that no one other than a scientist could discuss a science issue, but over the years, division between the "two cultures" has broken down, partly because the artificial 
division has been addressed directly in the Colloquium, and partly because faculty members' respect for one another has grown.

3. The theme should challenge the comfortable intellectual positions of the community. We chose to discuss Marx and the impact of Marx on the academy. We chose to discuss gender and power as reflected in society, the disciplines, and the university. We believe these confrontations have demystified the issues and sensitized faculty to tackling difficult, valueladen questions directly and publicly. Few issues seem troubling or impossible to discuss now.

4. Every participant should be accountable for the dialogue. Each participant should be responsible for giving a talk, being a respondent, or leading a discussion. Every year at the last minute, a few faculty members say, "Please let me come. I haven't done the reading, but I'll be just fine." Serious preparation through reading and taking a public role must be the entrée into the community. These expectations assure both equality and quality.

5. The parts of the colloquium should be integrated so that ideas are developed, built upon, and extended over the two days. Whenever we have failed to work on consciously pulling ideas together, the presentations have felt like a collection of random thoughts, and discussions have bogged down.

6. Each colloquium should end with a session focused on the question, "What does this mean to us as an intellectual community and what does it mean about what we do in the classroom?" This challenge has produced exciting ideas and significantly changed how and what faculty teach. The college has provided campus leadership for the commitment to introduce perspectives on race, class, and gender into the new required general education curriculum. Unlike Faculty Senate debates on other campuses, our decisions were calm, because the ideas had already been aired two years in a row in the less threatening environment of the Faculty Colloquium.

\section{Changing the Culture of the College}

Much is written these days about the culture of the academy and the corporation. Aspirations to excellence demand an attention to culture, for it is that invisible, yet powerful, set of shared expectations that supports efforts to develop responsiveness, effect improvement, and institute reform. Faculty development activities are aimed at improvement and 
reform - yet too often, they seem not to be able to affect the culture of the institution overall.

The culture of a campus is reflected in the classroom, the curriculum, and faculty interactions. It takes leadership and vision to change culture. It takes regular reinforcement to help faculty feel proud of their combined accomplishments. It also takes colleagueship to sustain and nourish the faculty. To discover again and again that we are friends even when we differ is exciting. To feel like students again, even as we grow grayer, is energizing. To find joy in learning, to feel we can take on new issues, to find our ideas challenged and appreciated, and to experiment with new ideas, even if only for a day or two, is revitalizing. The Faculty Colloquium has for eight years given the College of Arts and Sciences faculty an opportunity to come together annually to reaffirm their commitment to a common intellectual enterprise. 


\section{Appendx I}

\section{Faculty Colloquium Questionnaire}

Name:
Dept:-
Extension:

Please return this form promptly to Roberta Rubenstein, Department of Literature, Gray Hall, by November 10, 1980.

1. Would you be interested in participating in a Faculty Colloquium of the type described in the letter? (Of course, a "Yes" here does not actually commit you to anything; we are only concerned with determining the level of general interest.)

2. Please suggest one or more topics of interest to you that you believe might also interest your colleagues in other fields and serve as a focus for discussion with them (e.g., "America in an Interdependent World," the lives and contributions to knowledge of famous thinkers such as Galileo or Darwin). Would you be willing to lead a discussion?

3. Please give the title of some particularly important, stimulating, provocative or influential book or essay (classical or current) that you would like to see your colleagues read and discuss together.

4. Do you have any suggestions or recommendations to guide us in planning this Colloquium? 
5. What are the optimum times for scheduling such a Colloquium?

Please rank in order of preference and convenience:
A. Between semesters (December 20-January 12)
B. Spring vacation (March 9-14)
C. Week between final exams and Commencement (May 5-10)
D. Week after Commencement (May 11-15)
E. Suggested other time: 


\section{Appendix II}

April 1982

Dear Colleague,

Enclosed is the part of the Colloquium program for which you will have some responsibility. Every faculty member has graciously agreed to participate in some specific role to make the three days meaningful and absorbing.

Some of you will be making brief formal remarks. Others will be serving as discussion leaders. The task of leading a discussion does not imply that you should be "the expert," but rather that you should help promote a dialogue among members of the small discussion group. If you have any questions, please feel free to call a member of the planning committee.

To help assure a common reference point, we are suggesting that special attention be paid to the following readings:

\begin{tabular}{|c|c|c|}
\hline Tucker, Marx-Engels & Manifesto of th & mmunist Party \\
\hline & The German Ideology: Part I & $146-200$ \\
\hline & Estranged Labor & $70-81$ \\
\hline & Prefaces and Afterwards & $295-302$ \\
\hline & The Eighteenth Brumaire... & $594-617$ \\
\hline & Wage Labour and Capital & $203-217$ \\
\hline
\end{tabular}

\begin{tabular}{llr} 
Appleman, Darwin & \multicolumn{1}{c}{ The Descent of Man } & $132-208$ \\
& Mosaic of Darwinian Thought & $211-219$ \\
The Greatest Revolution & $279-284$ \\
Darwin, Philosophy and Theology & $297-324$ \\
Vogue of Spencer & $389-398$ \\
Sociobiology: The New Synthesis & $444-459$ \\
Biological Potentiality... & $460-464$ \\
Darwin Among the Poets & $513-518$ \\
The Tragic Fallacy & $519-521$
\end{tabular}

You will want to read all of the other three books and as much in addition from Marx and Darwin that time and interest allow. 
A copy of the complete program will be sent to you before May 4. We look forward to joining with our colleagues for this splendid venture.

Sincerely,

Colloquium Planning Committee

Richard Anderson, Biology

Karen Petersen, Sociology

Tom Cannon, Literature

Charles Crowder, Performing Arts 


\section{Appendix III}

\section{Faculty Colloquium}

May 1981

\section{America: The Two Hundred Year Experiment}

\section{Introduction}

The zenith of academic enterprise is the free exchange of shared ideas and experiences in the company of equals. This College of Arts and Sciences Faculty Colloquium is the modern echo of the convocation of academic leaders which has highlighted the history of our species since Antiquity. On a practical level, it is the opportunity to explore our very own natures - thinking, feeling, and being - in the context of diverse disciplinary backgrounds and in the fellowship of friends. The intellectual focus for this program stems from the desire to consider several dimensions of the two centuries of the American Experience. In this Colloquium, free from outside pressures, we come together to consider some of the forces, ideas, and decisions that are the prelude to the next phase of our history.

\section{Wednesday, May 6 - Kay Spiritual Life Lounge}

9:00 a.m. Coffee and Opening Remarks - Steve Grebe Theme: America: diminishing resources or increasing expectations?

9:30 a.m. Respondents to Richard Barnet and The Lean Years

Howard Wachtel Entire

Charles Crowder Steve Grebe

Break 
10:30 a.m. Defining the Problem:

\section{Discussion}

Does democracy work?

\section{Groups}

What is economic justice in a period of scarce resources?

Discussion leaders:

Jim Weaver and Austin Barron

Anthony Caprio and Myra Sadker

John Doolittle and Henning Leidecker

Carol Ravenal and Roberta Rubenstein

Lunch

1:30 p.m. Framing the Response: de Tocqueville,

Democracy

in America

What do we learn from history?

How do we use sociology and philosophy to analyze problems?

Opening Remarks by:

Entire

Richard Breitman

Group

Robert David

Harold Durfee

2:15 p.m. Discussion Leaders:

Discussion

Terry Murphy and Pierre Han

Groups

Gert Mueller and John Douglass

Roger Simonds and Vera Borkovec

Tom Cannon and Joe Blum

3:30 p.m. Closing Comments - Howard Wachtel 
Thursday, May 7 - Kay Spiritual Life Lounge

9:00 a.m. Coffee and Opening Remarks - Roberta Rubenstein Theme: To what extent is our future open? Entire

Group

9:30 a.m. Is human destiny controllable?

Wilson, On

\section{Human Nature}

Opening remarks on Wilson and sociobiology:

Alan Silberberg

Richard Anderson

Frank Turaj

Break

10:45 a.m. Using human resources to shape

Discussion the future:

Groups

Can you be what you choose to be?

Discussion leaders:

Bob Beisner and Linda Berenbaum

Barry Chabor and Bob Karch

Jeanne Roberts and Reomeo Segnan

Lunch

1:30 p.m. The problem of individual freedom Thoreau, in the world today

Walden

and "On the Duty of

Choose one of four groups: Civil Disobedience"

Freedom of the Press - Linc Furber

Role of the Dissident - Jim Malloy

Revisiting Walden - John Peacock

Continuation on Sociobiology

3:30 p.m. Closing Comments - Roberta Rubenstein 